\title{
Clinical Signs and Diagnostic Tests in Acute Respiratory Infections: Correspondence
}

\author{
Vijayasekaran $D^{1} \cdot$ Shanthi Ramesh ${ }^{1}$
}

Received: 22 June 2016 / Accepted: 22 February 2017 / Published online: 29 March 2017

(C) Dr. K C Chaudhuri Foundation 2017

To the Editor: The article entitled 'Clinical Signs and Diagnostic Tests in Acute Respiratory Infections' has highlighted the symptomatology and clinical presentation of respiratory infections in children. In this study, the authors have covered only acute upper respiratory infections [1]. They have retrospectively analyzed the clinical symptoms of acute respiratory tract infections along with three key investigations namely Rapid Strep A (RSA) antigen detection test, throat swab culture test and respiratory viral panel test (RVPT). These tests were done on each child at the time of admission.

The descriptive statistical analysis done on 1654 patients aged $0-16 \mathrm{y}$ reflected the current practice that the number of patients with a positive respiratory viral panel test are higher in the $<2$ y age group and the number of patients with positive rapid strep A test and positive throat culture test are higher in the $>6 \mathrm{y}$ age group. Based on the above findings, the authors concluded that in children less than $2 \mathrm{y}$ of age viral etiology is common and that bacterial etiology (Group A streptococcus) is common in children more than $6 \mathrm{y}$ of age. Hence, the authors have recommended the judicial use of antibiotics, particularly in young children with upper respiratory infection [2].

The study found no difference in RVPT positivity with regards to the four seasons. This is in contrary to the fact that viral respiratory tract infections occur most commonly in the "respiratory season" and this needs to be explained [3].

Again, the authors found no difference between the distribution of symptoms and RVPT positivity. Hence, we would

Shanthi Ramesh

drshanthiramesh@gmail.com

1 Department of Pediatrics, Sree Balaji Medical College \& Hospital, 7, Works Road, Chennai, Tamil Nadu 600 044, India like to know whether specific viral RT-PCR could be done to reduce hospital admissions. The authors could throw more light on this issue [4].

Mycoplasma pneumoniae infection has the ability to cause both lower and upper respiratory symptoms and it occurs throughout the year. Hence, if tests to identify M. pneumoniae had been included in the investigation panel, more information would have been obtained [5].

Authors have commented that symptoms like fever, cough, nasal discharge and nasal congestion are not specificfor infections of viral etiology and hence rapid determination of viral etiology is necessary to initiate appropriate anti-viral therapy and to limit the unnecessary use of antibiotics. This may not be applicable in developing countries and the suggestion of viral symptomatology which gives the initial lead to decide further management protocol cannot be ignored.

\section{References}

1. Dut R, Kocagöz S. Clinical signs and diagnostic tests in acute respiratory infection. Indian J Pediatr. 2016;83:380-5.

2. McCulloh RJ, Andrea S, Reinert S, Chapin K. Potential utility of multiplex amplification respiratory viral panel testing in the management of acute respiratory infection in children: a retrospective analysis. J Pediatr Infect Dis Soc. 2014;3:146-53.

3. Walke SP, Das R, Acharya AS, Pemde HK. Incidence, pattern, and severity of acute respiratory infections among infants and toddlers of a peri-urban area of Delhi: a 12-month prospective study. Int Sch Res Notices. 2014;2014:165152.

4. Wishaupt JO, Russcher A, Smeets LC, Versteegh FG, Hartwig NG. Clinical impact of RT-PCR for pediatric acute respiratory infections: a controlled clinical trial. Pediatrics. 2011;128:e1113-20.

5. Atkinson TP, Balish MF, Waites KB. Epidemiology, clinical manifestations, pathogenesis and laboratory detection of Mycoplasma pneumoniae infections. FEMS Microbiol Rev. 2008;32:956-73. 